\title{
Author Correction to: Language Policy and Language Acquisition Planning
}

\author{
Maarja Siiner, Francis M. Hult, and Tanja Kupisch
}

\section{Author Correction to:}

M. Siiner et al. (eds.), Language Policy and Language

Acquisition Planning, Language Policy 15, https://doi.org/10.1007/978-3-319-75963-0

\section{Chapter 3}

The original version of this chapter was inadvertently published with incorrect chapter author's affiliation. The correct affiliation is updated as:

Magdalena Antonia Hromadová

Charles University of Prague, Prague, Czech Republic

\section{Chapter 5}

The original version of this chapter was inadvertently published with incorrect chapter author's name and affiliation. The correct name and affiliation is updated as:

Subhan Zein

School of Languages and Cultures, The University of Queensland, Australia

The online version of the original chapters can be found under https://doi.org/10.1007/978-3-319-75963-0_3 https://doi.org/10.1007/978-3-319-75963-0_5

https://doi.org/10.1007/978-3-319-75963-0 